\title{
Ripple Reduction Using Seven-Level Shunt Active Power Filter for High-Power Drives
}

\author{
2 \\ N.M.Girish Kumar', M.V.Bramhananda Reddy ' ${ }^{2}$ B. Hemanth Kumar $^{3}$ \\ Associate Professor, Dept. of EEE, SV College of Engineering, Tirupathi, Chittoor (Dist) A.P, India ${ }^{1}$ \\ Assistant Professor, Dept. of EEE, SV College of Engineering, Tirupathi, Chittoor (Dist) A.P, India ${ }^{2}$ \\ Assistant Professor, Dept. of EEE, SV College of Engineering, Tirupathi, Chittoor (Dist) A.P, India ${ }^{3}$
}

\begin{abstract}
This Paper proposes the high-power non-linear loads and high-power adjustable-speed motor drives, such as

mainly used in electric novel ships, the shunt active power filter is proposed here to reduce the harmonic contents in source voltage and source currents of harmonic polluted three phase system supplying a Non- linear load and drives. The Shunt active filter is designed with Seven level cascaded H-bridge inverter. To handle the large compensation currents and provide better thermal management, two or more paralleled semiconductor switching devices can be used. In this paper two active filter inverters are connected with tapped reactors to share the compensation currents. Based on the joint redundant state selection strategy, a current balancing algorithm is proposed to keep the reactor magnetizing current to a minimum. The active filter topology can produce seven voltage levels. The harmonic filter reduces the harmonic contents in source currents as well as the source voltage multilevel shunt active filter does not require an interfacing transformer to connect it with the high power system. This is shown through simulation that the proposed active filter can achieve high overall system performance.
\end{abstract}

KEYWORDS: Shunt Active power filters, Total harmonic distortion, Power conversion, Power Drives.

\section{INRODUCTION}

Adjustable-Speed motor drives (ASDs) have found extensive application in a variety of high-power systems. One example is the electric propulsion system used in modern naval ships, the power ratings of which can be tens of megawatts. Typically, the front-ends of such ASDs employ a diode or a thyristor rectifier. In spite of their simple control and robust operation, these devices can generate voltage and current harmonics that might affect the operation of other devices in the same ac system. Conventionally, passive LC filters are used to mitigate harmonic-related problems. However, due to their large size and inflexibility, passive filters are gradually being replaced by active filters that utilize power electronic inverters to provide compensation for harmonics [1]

In Modern power quality electrical system, the power quality expressed as quality of voltage and quality of current are defines as "The measure, analysis and improvement of the bus voltage with sinusoidal wave form at rated voltage and constant frequency". There has been a sudden increase of non- linear loads, such as power supplies, adjustable speed drives etc. These non- linear loads draw non-sinusoidal currents from supply and causes distortion called harmonics.

These Harmonics further causes problems such as voltage neutral current, poor power factor etc. These voltage and current harmonics might affect the operation of devices in AC system. Conventionally, passive LC filters are used to reduce or eliminate harmonics related problems.

However due to their inflexibility and large size, passive filters are replaced by active filters. In that various active filter configurations, the shunt active filter system have number of advantages and constitute the optimal harmonic filtering solution. Generally, the ratings of shunt active filters are based on the rms compensating current and the rms terminal voltage for High- power applications such as ship propulsion systems. The large compensation current often requires parallel operation of two or more switching devices or active filters.

The schematic diagrams of shunt active filters with nonlinear $1 \mathrm{o}$ ad a $\mathrm{n} \mathrm{d} \mathrm{Hi} \mathrm{g} \mathrm{h} \mathrm{p} \mathrm{owe} \mathrm{r} \mathrm{d} \mathrm{r} \mathrm{i} \mathrm{v} \mathrm{e} \mathrm{(} \mathrm{Shipboard} \mathrm{p} \mathrm{owe} \mathrm{r}$ system) have shown in fig $1 \&$ fig 2 . Especially for high- power and high-voltage applications. In addition to their superior output voltage quality, they can also reduce voltage stress across switching devices. Since the output voltages have multilevel, lower $\mathbf{d v} / \mathbf{d t}$ is achieved Which is greatly alleviates electromagnetic interference problems due to high frequency switching. Over the years, most research work has focused on converters with three to five voltage levels, although topologies with very high number of voltage levels were also presented. It reduces switching devices current stress by distributing the compensation current between two parallel legs of an H-bridge topology. Shunt active filter also reduces voltage stress across the switches by utilizing a conventional threelevel flying capacitor topology. Overall, the configuration is capable of producing seven distinct voltage levels, and greatly reduces switching ripple in the compensating current 


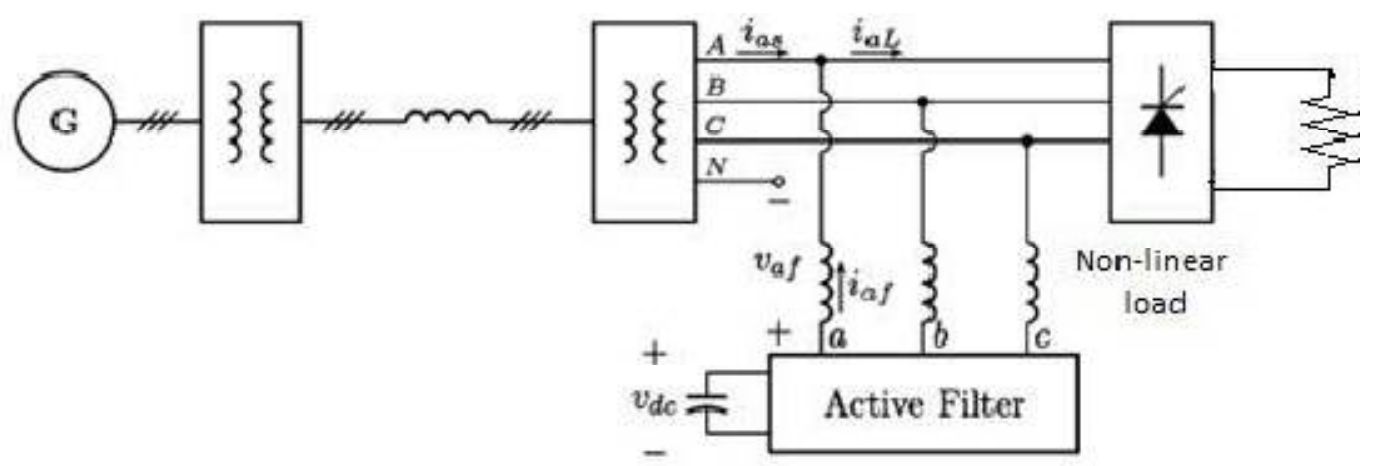

Fig.1 Active filter connection to a nonlinear power system

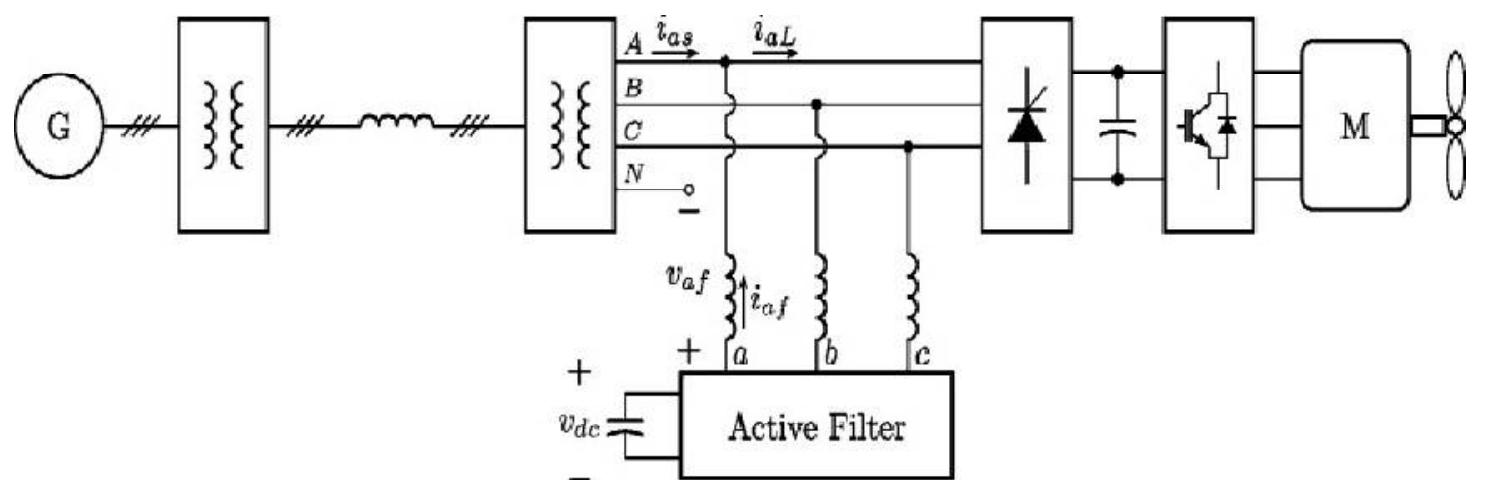

Fig.2. Active filter connection to a shipboard power system

\section{SHUNT ACTIVE POWER FILTER}

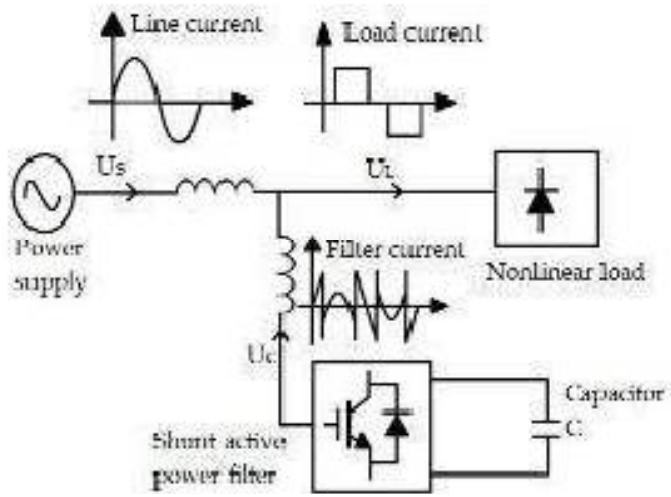

Fig.3 Schematic of Shunt active power filter

The Shunt topology is most popular as compared to others due to its performance and easy implementation. Active power filters has an alternate solution to passive filters. Active power filters are workable alternative for traditional passive filters to improve power factor and reduce harmonics in power system. The active power filter topology selection depends upon total harmonic distortion, power rating and cost of passive filter components, power factor, filter losses, switching losses, capability to provide harmonic isolation between load and supply, control complexity. The Active filter topology consists of an H-bridge configuration made from three-level flying capacitor branches. The schematic diagram of shunt active filter shown in fig. 3 .

It is essentially a voltage source inverter with capacitive energy storage (Cdc) shared by all three-phase. A total of eight switching devices are used in each phase. A tapped reactor is used to connect the two legs of the H-bridge. The reactor is typically wound to be center tapped, making the output line-to-ground voltages (for example Vag) the average of the voltages from each side of the H-bridge. Then, the line- to-ground voltages will have five distinct voltage levels. However, with this topology the tap is set at $1 / 3$ position. This results in seven distinct output voltages, and improves the power quality. 


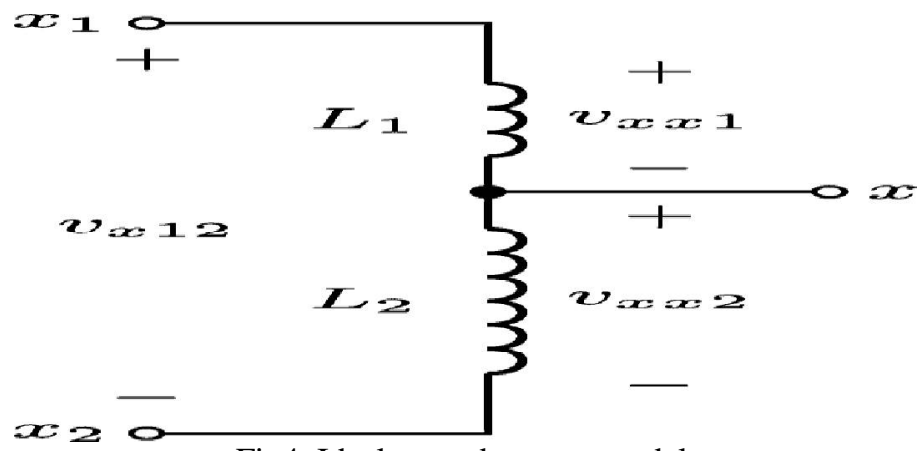

Fig4. Ideal tapped reactor model

\section{ACTIVE FILTER CONTROL}

To effectively compensate the load harmonic currents, the active filter controller should be designed to meet the following three goals: 1) Extract and inject load harmonic currents; 2) maintain a constant dc capacitor voltage; 3) Avoid generating or absorbing reactive power with fundamental frequency components.

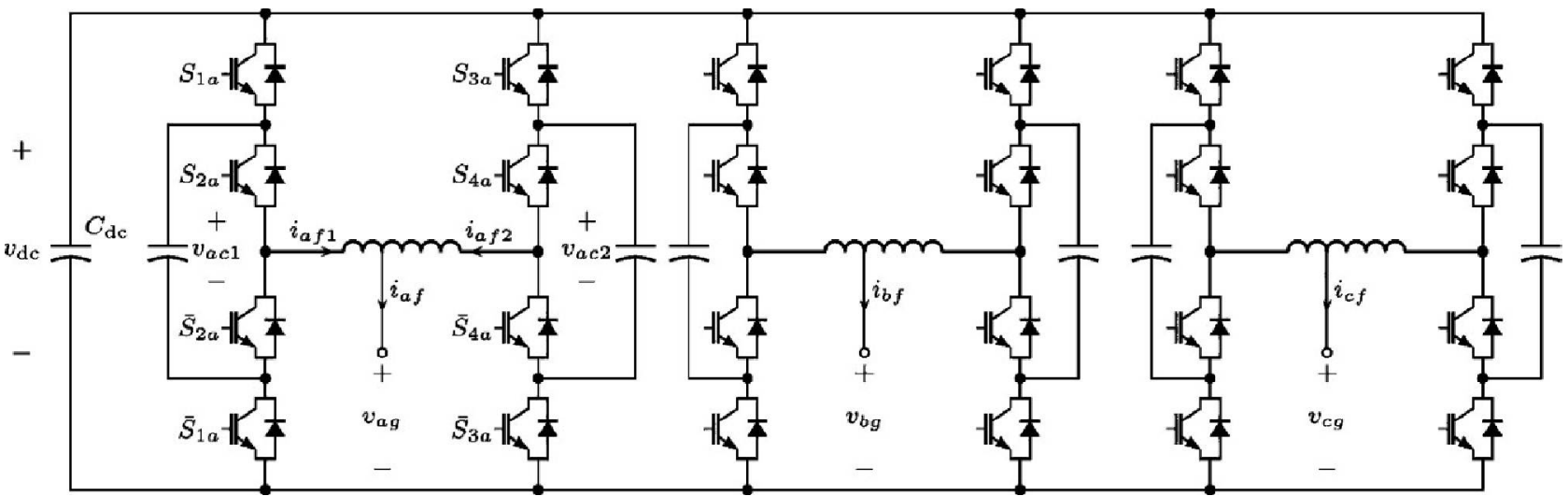

Fig.5 Proposed seven-level active filter topology.

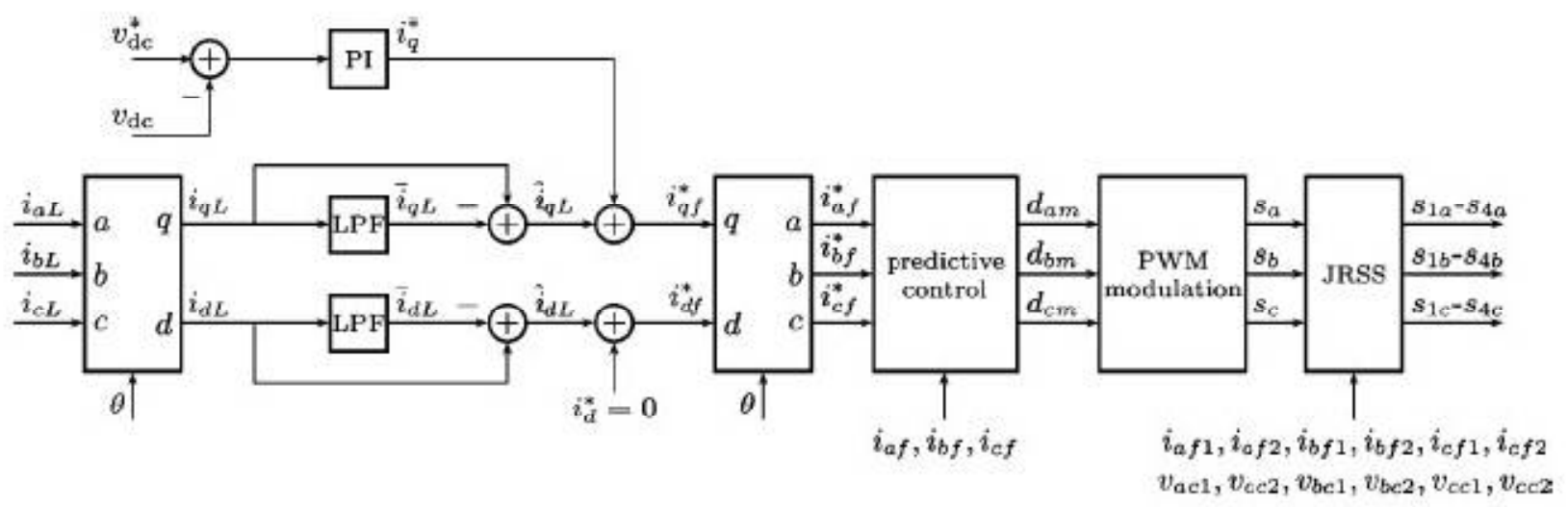

Fig.6 Active filter control diagram

\section{Capacitor Voltage Control}

For $\mathrm{t} h$ e active filter, it is Important to maintain the dc capacitor voltage at a constant value. Since the active filter topology is essentially identical to that of an active rectifier, similar control strategies for the active rectifier are applicable. The dc capacitor voltage is directly affected by the real power transferred across the active filter. To keep the voltage constant, ideally, no real power should be transferred. However, due to losses in switching devices and other components, a small amount of real power is needed. In the synchronous reference frame with the q-axis aligned with the voltage at the point of common coupling, the real power transferred can be expressed as $P=\frac{3}{2} v_{q s} i_{q f}$ 
This means that by adjusting the q-axis filter current, the real power can be effectively controlled. The capacitor voltage regulation is then handled by a simple proportional-integral

TABLE I

ACTIVE FILTER LINE-TO-GROUND VOLTAGES

\begin{tabular}{|c|c|c|c|c|}
\hline$s_{1 a}$ & $s_{2 a}$ & $v_{a 1}$ & $i_{a f 1}$ & Charging \\
\hline $\mathbf{O}$ & $\mathbf{O}$ & $\mathbf{O}$ & + & $\mathbf{O}$ \\
\hline $\mathbf{O}$ & $\mathbf{O}$ & $\mathbf{O}$ & - & $\mathbf{O}$ \\
\hline $\mathbf{1}$ & $\mathbf{1}$ & $v_{d c}$ & + & $\mathbf{O}$ \\
\hline $\mathbf{1}$ & $\mathbf{1}$ & $v_{d c}$ & + & $\mathbf{O}$ \\
\hline $\mathbf{O}$ & $\mathbf{1}$ & $v_{d c} / 2$ & + & - \\
\hline $\mathbf{O}$ & $\mathbf{1}$ & $v_{d c} / 2$ & - & + \\
\hline $\mathbf{1}$ & $\mathbf{O}$ & $v_{d c} / 2$ & + & + \\
\hline $\mathbf{1}$ & $\mathbf{O}$ & $v_{d c} / 2$ & - & - \\
\hline
\end{tabular}

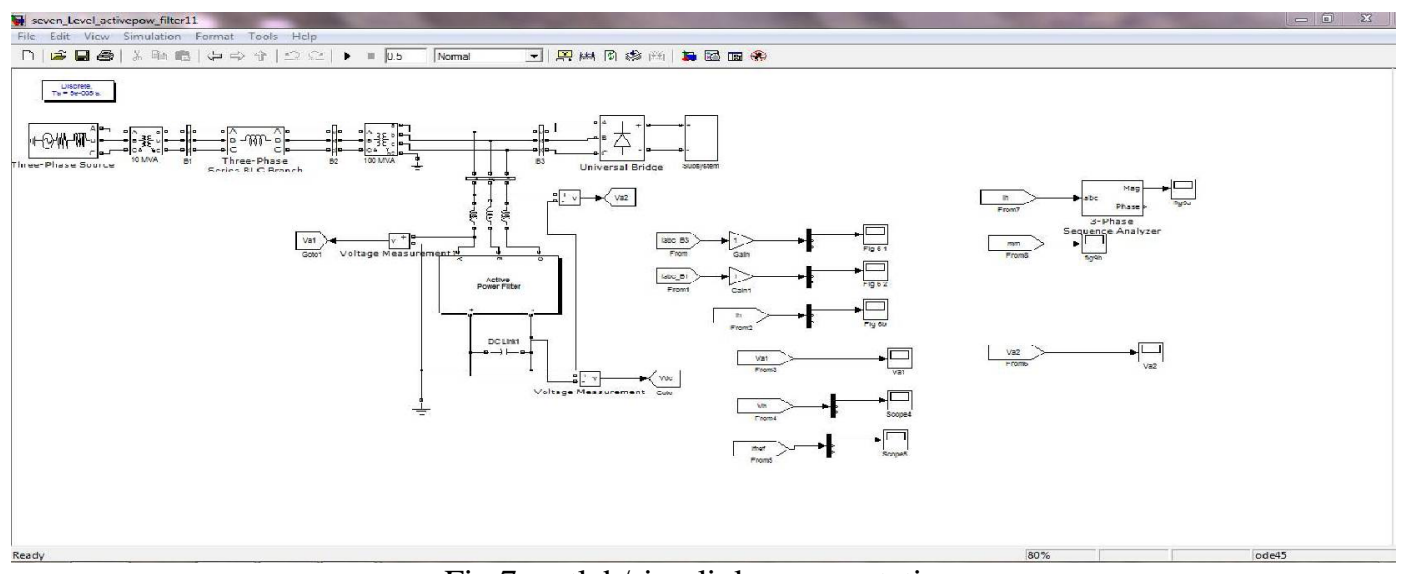

Fig.7 matlab/simulink representation

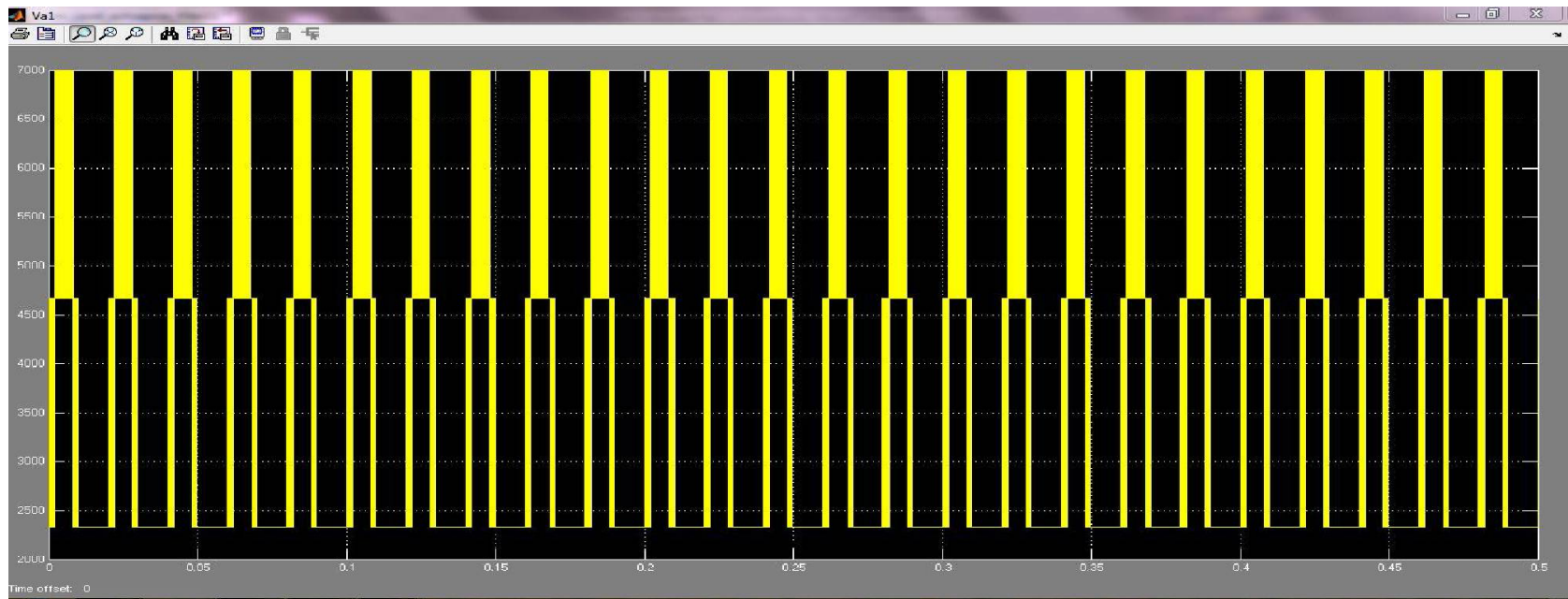

Fig.8 Vaf waveform 


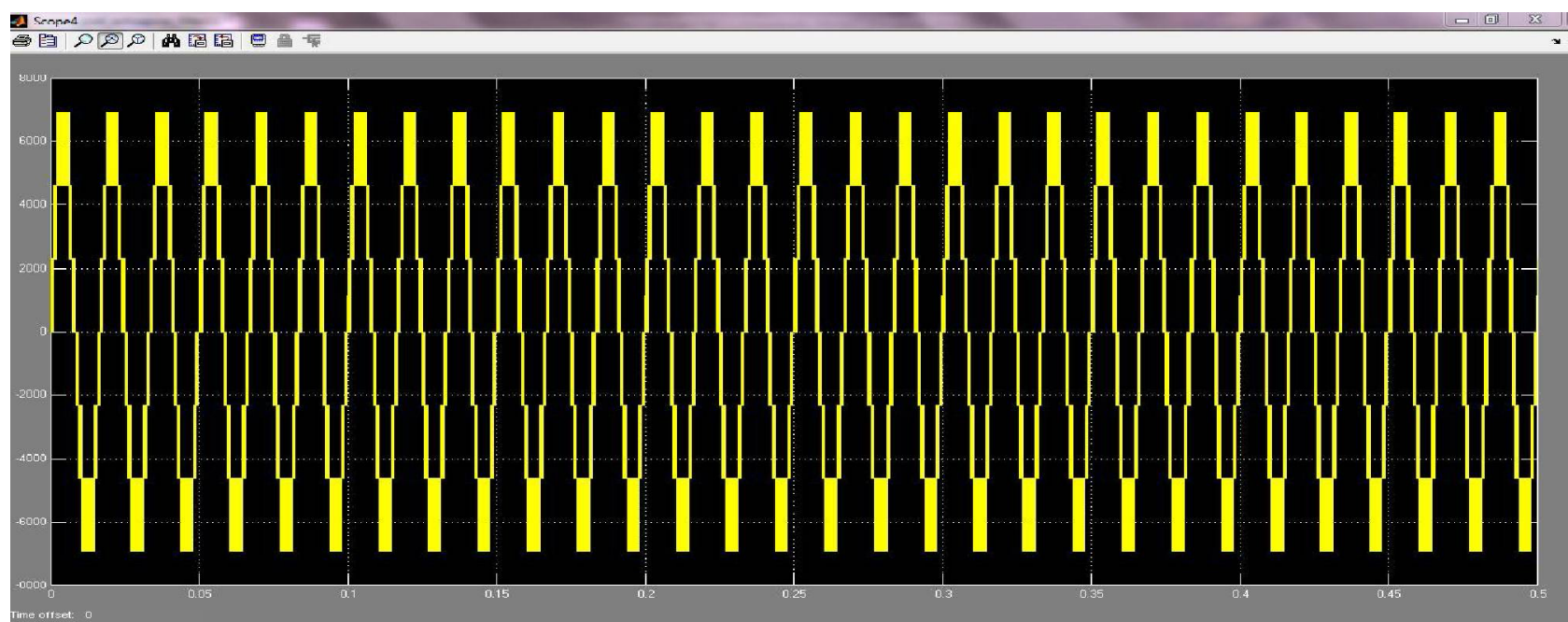

Fig.9 Vf waveform

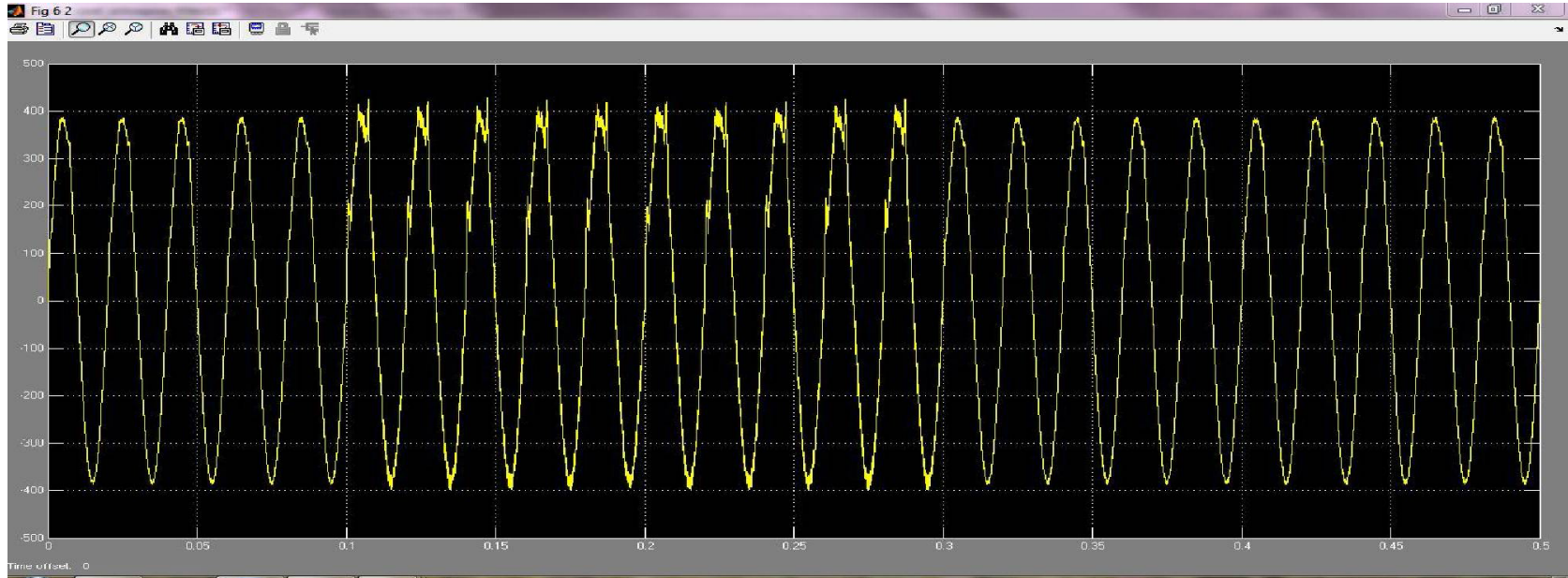

Fig.10 Ias waveform

Discrete,
$T_{s}=5 \mathrm{e}-005 \mathrm{~s}$.
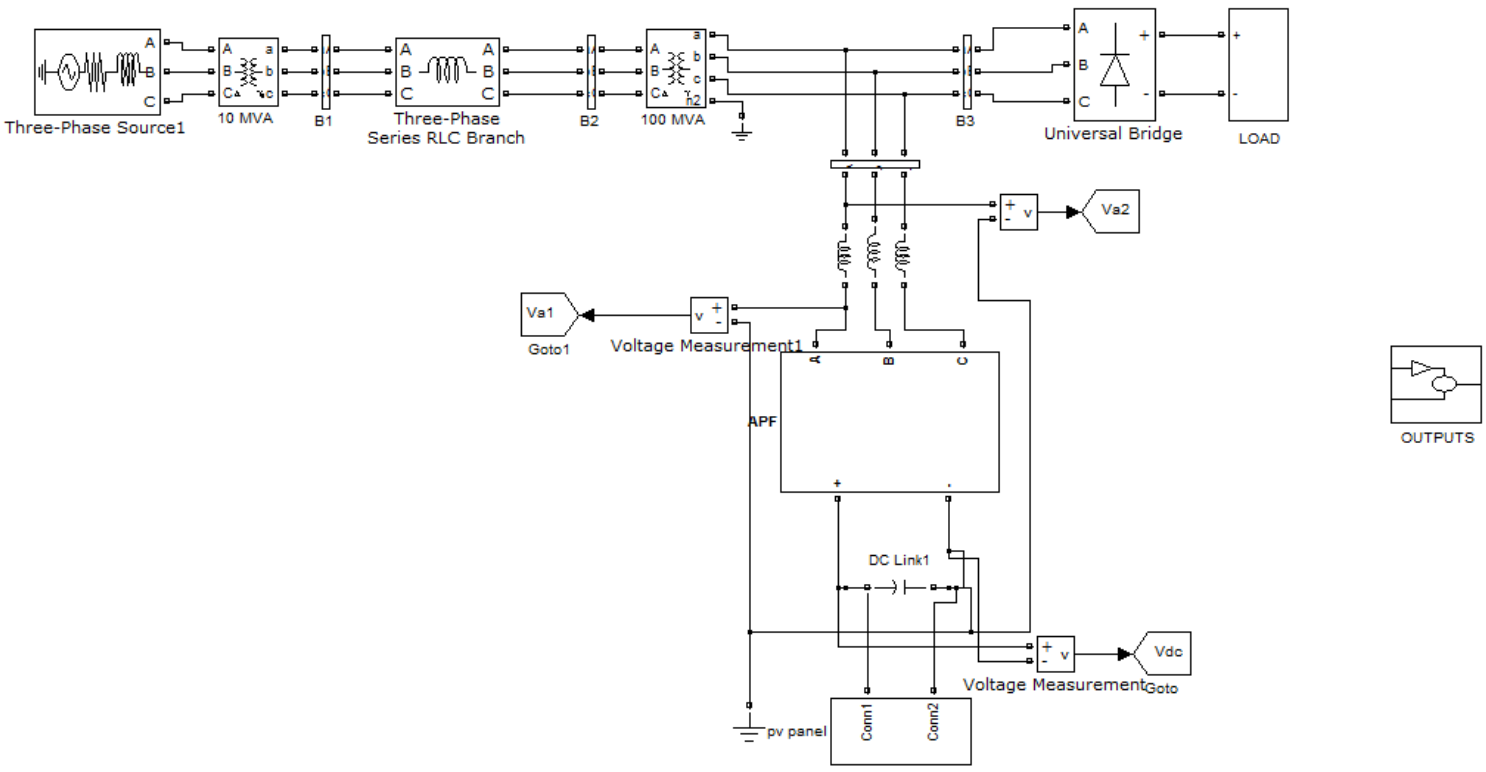

Fig.11 matlab system with PV Application 


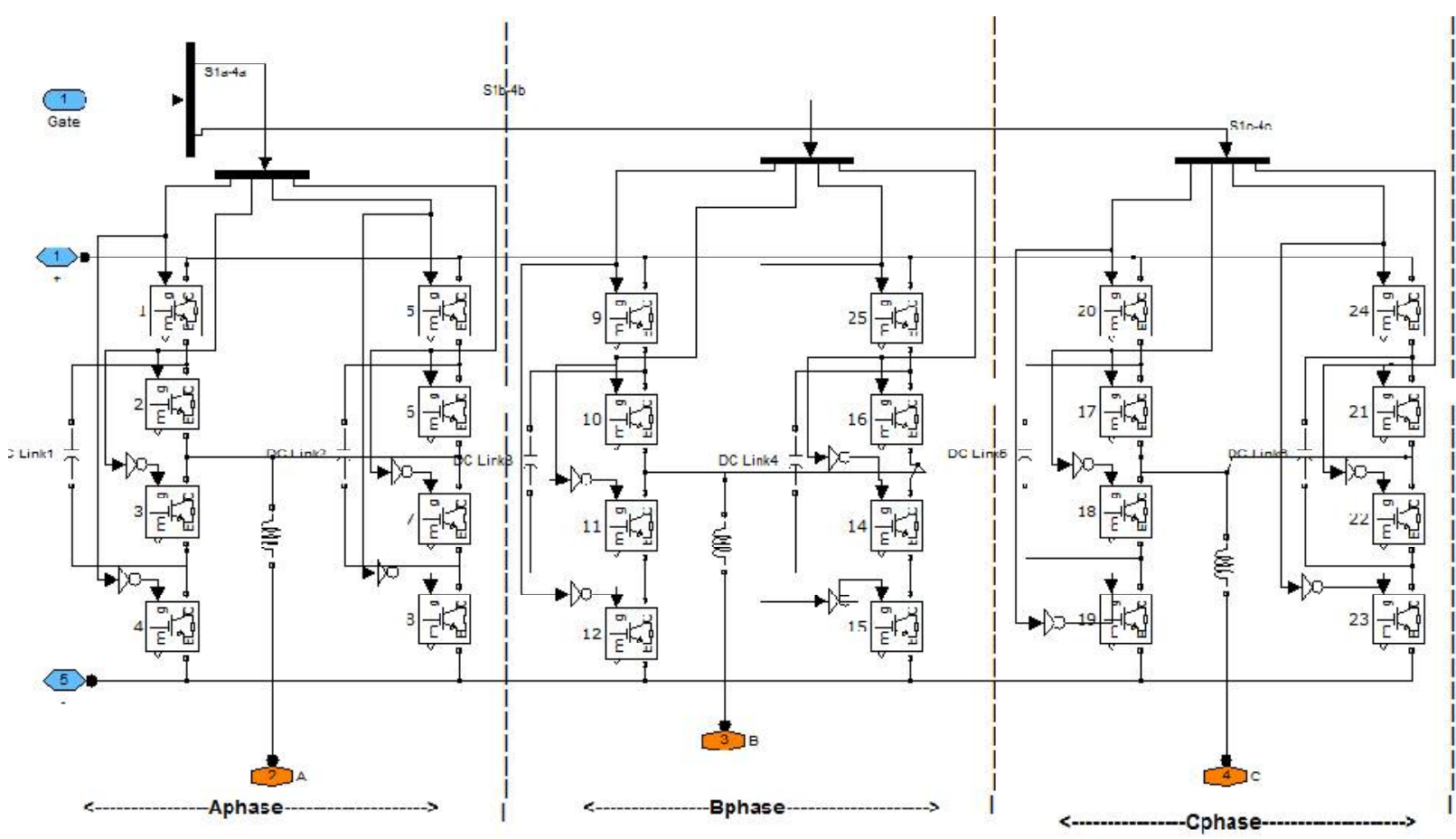

Fig.12 Seven level inverter configuration

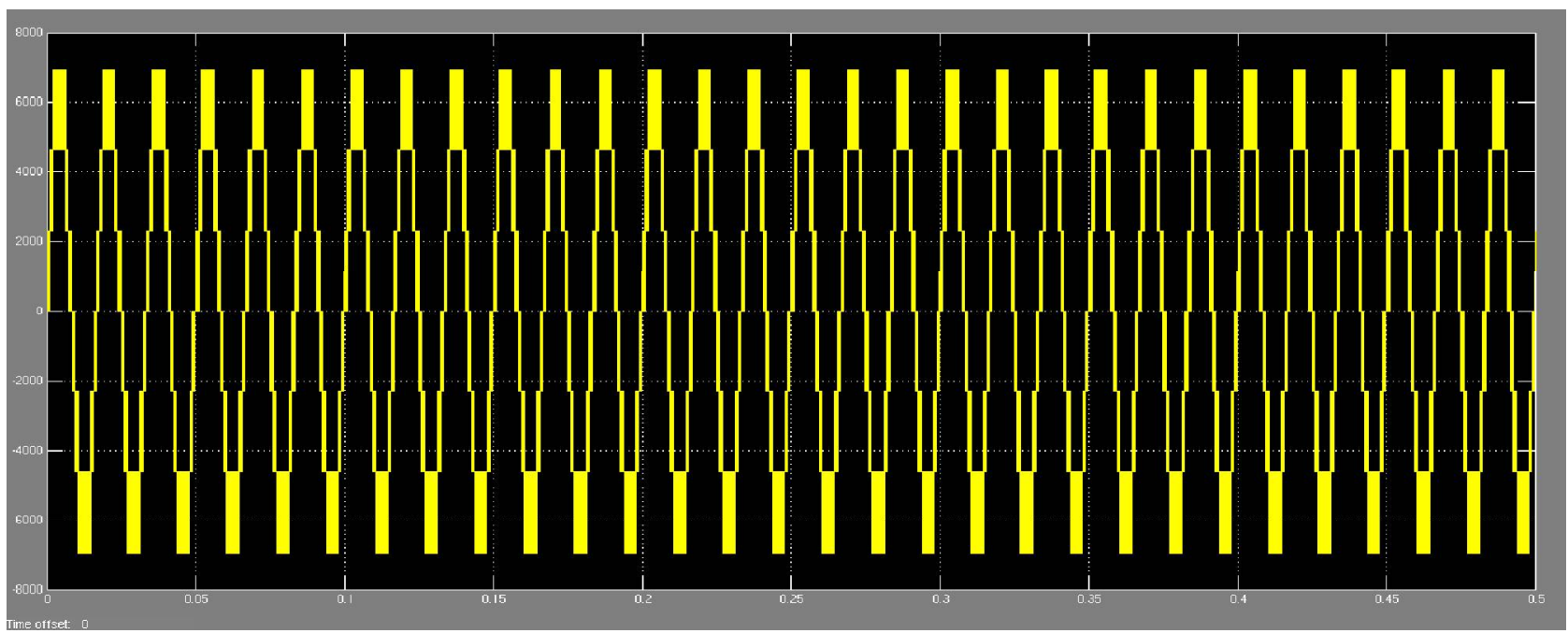

Fig.13 7 level output waveform

\section{CONCLUSION}

A new type of power converter has been introduced in this paper. The converter is based on parallel connection of phase legs through an inter phase reactor. However, the reactor has an off-center tap at one-third resulting in an increased number of voltage levels. Specifically, two three-level flying capacitor phase legs are paralleled in this way to form a seven- level power converter. The converter is utilized in an active filter application. The detail of the high-level control as well as the switching controls have been presented. The control ensures reactor current sharing a swell as flying capacitor voltage balance. The proposed active filter has been validated for a naval ship board power system.

\section{REFERENCES}

[1] B. Singh, K. Al-Haddad, and A. Chandra, “A review of active filters for power quality improvement,” IEEE Trans. Ind. Electron., vol. 46, no. 5, pp. 960-971, Oct. 1999.

[2] S. Bhattacharya, T.M. Frank, D. M. Divan, and B. Banerjee, “Active filter system implementation,” IEEE Ind. Appl. Mag., vol. 4, no. 5, pp. 4763 , 
International Journal of Advanced Research in Electrical, Electronics and Instrumentation Engineering

Vol. 1, Issue 4, October 2012

Sep. 1998.

[3] Z. Du, L. M. Tolbert, and J. N. Chiasson, “Active harmonic elimination for multilevel converters," IEEE Trans. Power Electron., vol. 21, no. 2, pp.

459-469, Mar. 2006.

[4] M. E. Ortuzar, R. E. Carmi, J. W. Dixon, and L. Moran, "Voltage-source active power filter based on multilevel converter and ultra capacitor DC link," IEEE Trans. Ind. Electron., vol. 53, no. 2, pp. 477-485, Apr. 2006

[5] B. R. Lin and T. Y. Yang, "Analysis and implementation of a three-level active filter with a reduced number of power semiconductors," Proc. Inst.

Electr. Eng. Electr. Power Appl., vol. 152, no. 5, pp. 1055-1064, Sep. 2005.

[6] M. Glinka, "Prototype of multiphase modular-multilevel-converter with 2MW power rating and 17-level-output-voltage," in Proc. IEEE Power Electron. Spec. Conf., 2004, vol. 4, pp. 2572-2576.

[7] J. Huang and K. A. Corzine, "Extended operation of flying capacitor multilevel inverters," IEEE Trans. Power Electron., vol. 21, no. 1, pp. 140147, Jan. 2006.

[8] P. Xiao, K. A. Corzine, and G. K. Venayagamoorthy, "A novel seven level shunt active filter for high-power drive systems," in Proc. IEEE Ind.Electron. Soc. Conf., Paris, France, Nov. 2006, pp. 2262-2267. 